\title{
English Collocations in the Tunisian EFL Context
}

\section{Hussien Almaktary}

Higher Institute of Applied Languages and Computer Sciences, Béja, Tunisia

\begin{abstract}
This study examines English collocations in the Tunisian EFL context. It delves into four areas of investigation: (a) familiarity with English expressions (idioms, phrasal verbs, and collocations) with more focus on the latter, (b) awareness of phraseology, (c) deviations of usage, and (d) correlation between collocation competence and the learners' performance in spoken and written skills. The investigation was conducted at the university level recruiting a sample of 84 EFL learners enrolled in the Department of English at the Higher Institute of Applied Languages and Computer Sciences in Béja. Three (quantitative and qualitative) instruments were used to collect data: a collocation test, a focus-group discussion, and document analysis. The findings showed that the informants' ability in using collocations was generally inadequate. The sources of violations of collocational linguistic behavior varied. The findings also revealed a positive correlation between collocational competence and oral and written skills of the participants. The study closes on a note of recommendation and call for further research.
\end{abstract}

Keywords: Collocations; EFL context; Tunisian EFL learners; phraseology

\section{INTRODUCTION}

English collocation, as a sub-category of phraseme, has been discussed within the domain of second language acquisition (SLA) and teaching methodology. Traditionally, the chunks of words in grammatical patterns were referred to as colligation, complementation, and construction (Castro \& Faber, 2014) and only in the 1950s were labeled collocations. They are now recognized as an integral part of second language competency. The ability to use them in the spoken and written discourse is mooted as an indicator of mastery of the target language. Prior research maintains that the significance of collocations is beyond dispute, and learning collocations is a substantial factor to improve the communicative competence of English learners (Attar \& Allami, 2013; Begagić, 2014; Kamal, 2014; Kiaee, Moghaddam \& Hosseini, 2013; Yazdandoost, Saleh \& Kafipour, 2014). Such studies have come up with results of a positive relationship between collocation and proficiency, but little empirical research has been conducted to determine which aspects of the language have the greatest impact.

Collocations are included in ELT materials under different labels: idioms, phrasal verbs, and the like. However, they have been selected in EFL contexts on an ad hoc basis though the importance of phraseology as an integral element of L3 lexical competence is undeniable (Koprowski, 2005). It is generally accepted that lack of phraseological awareness on the part of learners make them focus mainly on individual words rather than words in chunks. Even though learners in previous inquiries perceived collocations as an important aspect of linguistic competence, they- in practical terms- learn large numbers of words rather than studying how words collocate with other words, combined in collocational and colligational patterns.

\section{RATIONALE}

Prior research highlighted a big deal of English in ESL and EFL contexts. For instance, Kamal (2014) investigated the topic in the Egyptian context; Kiaee, Moghaddam, and Hosseini (2013); Biskri (2012) in the Algerian context; Al-kadi (2014) in the Yemeni context, Attar and Allami (2013) and Yazdandoost, Saleh and Kafipour (2014) in the Iranian context, to mention a few. Whereas idioms and phrasal verbs have received ample attention, collocations are still an area of much debate and have not sufficiently versed. There is room for further investigation. This study builds on ideas stemming from recommendations of previous studies in similar contexts. To begin with, some studies investigated a few patterns of collocations with an overlap with phrasal verbs and idioms. Guided by 
the limitations of such studies, the researchers suggested including other collocational patterns in further research. For instance, Bhumadhana (2011) endorsed demystifying collocations of these types: adjective-noun, adverb-adjective, and adjective-preposition collocations. The author suggested using different types of data elicitation (e.g. cloze tests, multiple choice questions, and error corrections) as well as authentic production such as students' essays. As such, the study at hand included seven collocational patterns to extend the scope of enquiry.

Moreover, although the theme of this study is not state-of-the-art, it is replicated in a context where English is not an L2 but L3 ${ }^{1}$ - Tunisia, a francophone country. There is a need to assess the Tunisian learners' abilities in using English collocations so that to enhance their overall English competence. Students may be aware of the significance of learning and using collocations. The study also draws the teachers' attention to handling collocation teaching adequately. In this regard, this study was stimulated by recommendations of Wangsirisombat (2011) and Mongkolchai (2008) in the Thai EFL context where English is taught as EFL as well as Shehata (2008) in the Arab-speaking context. Similarly, the insightful ideas of Duan and Qin (2012) reporting from China were inspiring, too. In a nutshell, previous research studies have provided an incentive to examine such a linguistic phenomenon in the Tunisian EFL context which is influenced by Arabic language (L1) and French language (L2).

\section{GOAL AND OBJECTIVES OF THE STUDY:}

This study intends to explore the status of English collocations in terms of learners' familiarity with the collocational patterns, their awareness of phraseology for their English as well as relative contributions of collocations to their overall performance in spoken and written English at the university level. More specifically, it is an attempt to achieve the following objectives:

- Assessing the Tunisian EFL students' knowledge of English collocations.

- Identifying the sources of violations in their using English collocations.

- Examining students' awareness of phraseology.

- Correlating learners' level of collocation competence to their English oral and writing performance.

\section{QUESTIONS OF THE STUDY}

The objectives of the study were converted into the following research questions.

1. To what extent are the Tunisian EFL learners able to recognize and use English collocations?

2. What are the causes of violations in their collocations usage?

3. Is the Tunisian EFL students' performance on a collocation test correlated with their performance on oral and writing achievement tests?

\section{LITERATURE REVIEW}

\subsection{English in Tunisia}

Tunisia, a former French colony located in the north of Africa, on the Mediterranean Sea, is a good example of multilingualism. The linguistic map in Tunisia is quite complicated and beyond the scope of the study at hand. However, it would be useful to provide a brief account on the linguistic situation in the country. Modern Standard Arabic is the official language with French influence in daily communication, press, media, online forums, social networks, radio, and TV broadcasting. Daoud (2001) argued that by the time Tunisia gained independence in 1956, the French language was prevailing in the administrative and educational systems. Daoud stated that "it is currently difficult for academics and journalists to clearly distinguish its status as a second or foreign language" (p.8). The French influence is apparently evident in day-to-day life aspects of the Tunisians. Even after independence, in spite of the efforts and progress in Arabization, Tunisia continued to use French as a tool for modernization and development (Daoud, 2000, 2001).

\footnotetext{
${ }^{1}$ Whereas the term second language (L2) refers to any language other than the first language, L2 in this study refers to French language and L3 to English.
} 
Although English was officially present in Tunisia since independence, only quite recently- under growing demands for English to meet modern science and technology- it has received remarkable attention (Daoud, 2000). It is now taught an ESP and EFL throughout the country. Also, it has been used for emancipation and power during the last few decades (Labassi, 2008), and particularly after the 2011 Revolution, English has gained attention more than any time before (Boukadi, 2013). Stimulated by globalization and modern technology (Aouina, 2013), English has gained "ground over Arabic (L1) and French (L2) in schools with the globalization movement and the expansion of technology" (Boukadi, 2013, p. 14). Besides being a school subject, English is taught at the higher level in over 50 tertiary-level institutions primarily in the business and economics domain, as well as in the sciences, engineering, and medicine; and, similarly, hundreds of students are enrolled in English language programs in several institutions throughout the country (Dauod, 2000).

Furthermore, Tunisia has witnessed inceptions of a series of conferences, workshops, and symposia, organized regularly with relevant themes such as research methodology, ELT, ESP, theoretical and applied linguistics, literature, and British and American studies. Despite the emergence of English as another linguistic option and despite the worthwhile formal attention, some Tunisian teachers/researchers (e.g. Boukadi, 2013; Dauod, 2000; Labassi, 2008) sustain that English in Tunisia encounters problems in schools and society. One of these hurdles is of a cultural dimension; some Tunisians still "associate these languages with colonialism, imperialism, and imported cultures that might have negative impacts on society" (Boukadi, 2013, p.16). Also, some believe that English, unlike French, is irrelevant to their daily activities and careers. For EFL learners, English does not have an immediate need outside the classroom. However, they realize that it is gaining ground in Tunisia at the expense of the French language.

\subsection{Collocations, Idioms, and Phrasal Verbs}

In the literature, collocations, idioms, and phrasal verbs have been discussed under the umbrella of phraseology - the way words and phrases are patterned and used. In other words, it is the study of fixed expressions. As there is no watertight definition of collocations, some researchers refer to these three terms as synonymous in sense of their essence as a collective whole. Nevertheless, some other writers make a distinction between them with a reference to collocations as words/phrases frequently used with other words or phrases in such a way that sounds correct to speakers of the language (e.g. heavy snow), while idioms are expressions semantically and syntactically restricted - their meanings are different from the meaning of their individual constituent words, as in this example: He kicked the bucket, meaning died. On the other hand, a phrasal verb is a combination of words used like one verb. It consists of a verb and a particle (adverb or preposition) as in the following examples - go on, give up, take over, come up with, and the list goes on. That is to say, the term of 'collocations' means juxtaposing words in a certain sequence, and this combination results in a pattern of language known as collocations. Basically, the three items (collocations, idioms, and phrasal verbs) are expressions with a sharing tenet - components fixed togetherness in a certain order.

As such, the focus of the study at hand is undertaking collocations in light of the difference in definitions of the other two terms. Oxford Collocations Dictionary (2009) refers to collocation as "the way words combine in a language to produce natural-sounding speech and writing". For example, the collocation 'heavy rain' or 'strong wind' are common expressions in English while 'heavy wind' and 'strong rain' do not exist. In corpus linguistics, a collocation is a sequence of words or terms that cooccur more often than would be expected by chance.

In a similar vein, Hadi (2014) defined collocations as "habitual co-occurrence of words in a linguistic form (p. 566). Likewise, in Al-kadi's (2014) study, collocations and idioms are taken as two ends of the same continuum wherein collocations on one end, idioms on the other end and phrasal verbs are somewhere in between the two extremes.

\subsubsection{Classifications of Collocations}

The term 'collocation' in its linguistic sense is relatively new, and there is still considerable dispute about its definition. This disagreement and even confusion about it make some linguists treat collocations simply as 'fixed phrases'. The fixed expressions, prim and proper, alive and kicking, back and forth, wear and tear, toss and turn, or idioms such as rains cats and dogs are treated as expressions of fixed sequences of words. For more examples, refer to Oxford Collocations Dictionary for Students of English by Crowther (2003) and English Collocation in Use by McCarthy and O'Dell (2005). These are two good references of collocations. 
For the sake of simplicity and clarity, several researchers have provided some classifications of collocations. They broadly divide them into lexical and grammatical types. A distinction may be made between these two general types. A lexical collocation is a construction where a verb, noun, adjective or adverb forms a predictable connection with other words, as in the following examples:

- Adverb + adjective (e.g. completely satisfied, totally different, fully aware).

- Adjective + noun (e.g. maiden voyage, fast food, regular exercise).

- Noun + verb (e.g. lions roar, birds tweet, dogs bark).

- Verb + noun (e.g. make bed, commit murder, do homework).

- Noun + noun (e.g. summer school, ceasefire agreement )

- Verb + expression (e.g. fill with horror, run out of money, burst into tears).

- Verb +adverb (e.g. learn quickly, listen carefully, whisper softly).

On the other hand, a grammatical collocation is a construction where, for example, a verb or adjective is followed by a particular preposition, or a noun followed by a particular form of a verb, as in the following examples:

- Verb + preposition (e.g. relay on (NOT relay ef; depend on NOT ef)

- Adjective + preposition (e.g. sick of (NOT sick at; good at NOT in).

- Noun + particular form of a verb (e.g. decision to lift it (not decision lifting it).

Another classification of collocations is categorizing them into open, bound and restricted collocations. Open collocational is a list wherein certain words accept adding endless words, bound collocations are bound to certain words, and restricted collocations are restricted to a few patterns. Open collocations might be understood by the literal meaning of their components, unlike restricted collocations in which one word has a figurative sense not found outside that limited context. A bound collocation is a "bridge category between collocations and idioms" (Nofal, 2012, 83).

\subsubsection{Importance of Collocations}

Collocation is a linguistic feature of a language. For instance, collocations make a big deal of the English language, and ESL/EFL learners- at every level- have to use them in their spoken and written English. Noticeably, using collocations enables learners to speak more fluently and write more effectively (Alhaysony, 2017). It makes their speech clearer, more natural and easily understood. It also helps them sound native-like (Al-Khawaldeh, Jaradat, Al-momani \& Bani-Khair, 2016). Besides, using collocations is a useful strategy providing rich and alternative ways of self-expression in different situations. Moreover, relying on evidence from the field of psycholinguistics, the human brain remembers words in chunks/blocks more easily than single words.

Famous writers and ELT experts such as Ur (1996), Richards (2002), Thornbury (2009) argue that the collocational competence is necessary for English learners to simultaneously promote EFL and ESL learners' macro-skills (productive \& receptive skills). Richards (2002) proposed the term 'restriction' for collocational structures in producing lexical or grammatical collocations correctly. Previous studies illustrate the significance of collocation as a research area and essential segment of language to be introduced to ESL/EFL learners. The effect of collocations on English proficiency was evident in various EFL and ESL contexts. For example, Yazdandoost, Saleh, and Kafipour (2014) explored the relationship between collocational competence and L2 proficiency of Iranian EFL learners. Results showed an influential role of collocation knowledge in English learning, and knowledge of collocation proved to be a prerequisite for successful language learning in the Iranian context.

Some other studies demonstrated the effects of collocations on different aspects of English in other contexts. For instance, Hadi (2014) studied the performance of 100 Iraqi EFL undergraduates to find out about their abilities in using lexical collocations. The study dug into the sources of difficulties that the informants encountered in using English collocations. Results showed an overall poor collocational proficiency. The findings indicated that there were three sources of this low competence: substitutions, literal transfer, and generalizations. The study recommended that collocations are necessary for mastering the target language (English). 
Similarly, Bhumadhana (2011) studied the problems of using collocations, and the relationship between collocation use and writing ability of 155 English majors at Walailak University in Thailand. The study divided the sample- according to their familiarity with academic verb collocations- into three categories: low, moderate and high categories. This classification was based on the results of an academic verb collocation writing test of 18 academic verbs on an academic word list. The findings showed that there was a positive relationship between the use of academic verb collocations and writing abilities of students at the significant level of .05. Likewise, the findings indicated the importance of collocations in language learning and teaching in the classroom.

Alike, Brashi (2017) unearthed the ability of some Saudi EFL learners in using English verb + noun collocations through a collocation test. The study reported some difficulties that encountered the participants in producing English collocation of this type -verb + noun. The author argued that this could be attributed partially to the influence of L1 (Arabic) and lack of collocational competence of L2 (English).

\subsection{Collocation Teachability and Acquisition}

In the literature, learning and teaching English collocations is not straightforward. There have been difficulties, challenges, and strategies associated with this area of research. Why are collocations difficult to learn and master? Hadi (2014) responds that collocation patterning is arbitrary; it does not follow particular rules. It is highly subject to the native speakers' tendencies -and regular use- of using the target language and culture. In other words, collocations are unpredictable. The arbitrariness of collocations causes difficulties for those who learn English in an environment which lacks exposure to authentic English. It requires a greater degree of competence with the English language to combine them correctly in language productions of EFL learners.

Kamal (2014) investigated the effect of explicit and implicit instruction on the acquisition of English collocations of this type (verb + noun) in the Egyptian context, where English is taught as an L2. The study showed that the explicit method was more beneficial than the implicit one, a result similar to previous research which shows that the explicit method is mainly revolved around exercises and drills, and the implicit method mainly depends on repetition and input overflow. The researcher suggested using both explicit and implicit instructional methods for teaching collocations taking into account the strengths and weaknesses of each instructional method.

In the same vein of research, Duan and Qin (2012) studied English collocation learning/teaching in the Chinese context. The study asserted that collocations should not be taught as words (with a purpose to increase the size of words), but rather as a whole of patterns with certain shape and meaning. Touching upon the importance of collocations, Duan and Qin compared the Chinese Language to the English Language in terms of phraseology, providing two reasons for errors in using English collocations: Mother-tongue interference (Chinese) and over-generalizations.

In the Arab-speaking context, Shehata (2008) conducted an empirical study to explore effective ways of developing English collocational knowledge of the Arab EFL learners. The author explored the issue in two environments: ESL (the Arab learners living in the United States of America) and EFL (Egypt). The learners in the former context were seven Egyptian, two Iraqis, eight Jordanian, eight Saudis, two Kuwaitis, two Moroccans, three Sudanese, and three Syrians, and they were all graduates and undergraduates at Ohio University. Findings showed that the learners' L1 (Arabic) and their learning environment had influences on the acquisition of L2 (English) collocations. Also, there was a positive correlation between learners' collocations and the amount of exposure to the language. It was concluded that learners' knowledge of receptive collocation was broader than that of productive collocations.

Generally speaking, collocations can be learned and taught explicitly and implicitly. The former method is a "conscious awareness and intention to learn" (Brown, 2000, p.217). It is a teacher-centred and a deductive process that EFL/ESL learners employ to get the structure of the presented information. The latter, according to Brown, is "learning without conscious attention or awareness" of the presented subject-matter. It is an inductive teaching that has no plainly expressed of subjects. Many textbooks and collocation books follow these two methods, and there seems to be no evaluation of their effects in EFL contexts.

Putting it in the Tunisian context, English collocations are embedded in the teaching of some English courses. For instance, a course title, Everyday English, was taught in 2015-2016 at the Faculty of 
Humanities and Social Sciences, University of Tunis - a two-hour class taken in the second year of the English program. As the course guidelines show (see Appendix B), one of the objectives of the course in question was developing students' knowledge of English collocations and idiomatic expressions used in authentic situations. However, no available data shows how such classes were conductedclassroom teaching is irretrievable; the class sessions are neither taped/video-taped nor archived. However, from my teaching experience in the Tunisian context, I can say that collocation teaching-like teaching other aspects of the language- undergo similar teaching methods prevailing in the Tunisian context: lecturing, teacher-centeredness, an exam-oriented teaching/learning environment.

\subsection{The Relationship between Collocations and English Performance}

Examining the association between collocational competence and written/spoken performance of EFL learners has been examined in the worldwide contexts. For instance, in the Iranian context which is an example of EFL context, there is a plenty of studies. To mention a few, Heidarnezhadian, Aliakbari, and Mashhadi (2015) studied the impacts of collocational expression on writing competence, Kiaee, Moghaddam, and Hosseini (2013) investigated the effect of teaching collocations on reading comprehension, and Attar and Allami (2013) examined the effects of teaching lexical collocations on speaking abilities. Similarly, Yazdandoost, Saleh, and Kafipour (2014) uncovered the relationship between collocations and proficiency in the language skills: listening, speaking, reading and writing. All these studies reported positive effects of collocations on the Iranian learners' English skills.

Similarly, Kiaee, Moghaddam, and Hosseini (2013) investigated the effect of teaching collocations on enhancing Iranian EFL learners' reading comprehension through a quasi-experimental study (control vs. experimental groups). The statistical results of t-test showed that that the students in the experimental group outperformed the control group in reading comprehension. The study concluded that teaching collocations is significant to enhance EFL learners' reading comprehension skills.

In the Iranian context, too, Attar and Allami (2013) studied the effects of teaching lexical collocations on speaking skills of Iranian EFL learners. The result of paired sample t-test showed that the participants' speaking ability in the experimental group significantly improved as shown in the posttest results. The analysis also revealed that after the collocation instruction in the experimental group, the participants' performance increased remarkably. Moreover, the result of ANCOVA displayed that the participants had positive attitudes towards explicit instruction of collocations.

In India, Shahryari and Motaharinik (2015) considered the influence of teaching collocations on essay writing and speaking abilities of 69 learners from English Center Institute in Mysore city. This sample was divided into control and experimental groups. The control group was taught in the conventional method and the experimental group received collocation instruction. The results showed that the students' in the experimental group outperformed their counterparts insofar as writing performance and speaking ability were concerned.

Likewise, Al-kadi (2014) studied the idiomatic competence of 63 Yemeni EFL learners at the university level and its relationship with the students' performance in listening and speaking. The study compared the performance of two groups of learners: a group of high achievers and a group of underachievers. The scores of both groups in listening and speaking were compared to their scores of an idiom test. The result showed that students with high idiomatic competence were more fluent than their counterparts.

In another context where English is a third language, similar to the context of the study at hand, Mounya (2010) investigated teaching lexical collocations and their relevance to writing proficiency of Algerian learners of English. It was an experimental study unraveling correlation between collocation learning and English writing proficiency. The study adopted pre-posttests of English proficiency to assess the proficiency of 48 Algerian students learning English as an FL. The results showed a positive correlation between the participants' collocations use and writing abilities. According to Mounya, this was due to the teaching of collocations as it appeared only in the experimental group, not in control group.

In the Algerian context, too, Biskri (2012) studied, through a mixed method approach, the students' use of lexical collocations and oral proficiency. The study specifically examined and described the 
effect of awareness of lexical collocations on EFL students' oral proficiency. The findings implicated that L2 learners needed an awareness of phraseology in their English. According to the author, an official intervention in this regard helped the undergraduates to improve their collocation abilities.

\subsection{Difficulties and Strategies of Collocation Learning}

Being quite unpredictable, arbitrary, and unteachable, collocations strain learners of English as a foreign language. This issue has been discussed in several contexts and some strategies were suggested accordingly. For instance, Wangsirisombat (2011) analyzed types of collocational errors and the strategies used by the Thai learners of English working in an international organization to produce collocations. The instruments recruited in the analysis were a test, email correspondence excerpts, and questionnaire. Common errors were found in the patterns of adjective + noun, verb + noun, and adverb + adjective. The participants used two common strategies: approximate translation and word retrieval strategy. In the same vein, Shiri, Sadighi, Azizi, and Nekoueizadeh (2017) analyzed types of errors by EFL Iranian advanced learners. The study showed six types of collocations that posted difficulties in using Adjective + Noun collocations, as the most difficult combinations and the least problematic ones were those of Adverb + Adjective and Noun +of + Noun.

In the Arab context, Alhaysony (2017) studied major difficulties of understating idiomatic expressions by 85 university students in the Saudi EFL context. The study outlined the strategies that the participants tend to use so as to overcome such difficulties. Similarly, Al-khawaldeh, Jaradat, Almomani, and Bani-Khair (2016) studied the same issue in the Jordanian context - the difficulties of learning the figurative idiomatic language as experienced by 150 learners at the Hashemite University. Both studies attributed the poor competence of the informants' to a lack of idiomatic competence. Despite the limited awareness of the most frequently used idioms, the learners had overwhelming desire to learn them.

Common suggestions laid out by the two studies are outlined below.

- Helping students use idioms through examples in interactive situations where students get encouraged to analyze the correct use of idioms.

- Being aware of the fact that collocations are culturally-bound with figurative meanings that differ from the literal meanings of their constituents.

- Learning idioms with conceptualization in both first and foreign or second language. Connecting the learners' L1 (their first-hand knowledge) and L2 (experience of idioms of L2) is an advantage.

- Textbooks should include collocational components of ample collocational patterns.

Begagić (2014) provided an elaborated discussion of collocations: the notion of collocations, classifications, and their importance for English language students, and the productive and receptive knowledge of lexical collocations of the learners. The study came up with important results. The students' in question -40 English learners whose L1 was Bosnian, Croatian and Serbian- had poor collocational knowledge. According to the author, this can be interpreted by interfering with the collocations of their mother tongue, but also due to the way students were taught English.

This review illustrates the positive impacts of collocation learning/teaching. It has been positively evidenced in different ELT contexts ranging from China, India, Iran through the Arab peninsula and North Africa. Although the samples were relatively small, e.g. Wangsirisombat (2011) recruited only 30 EFL learners, Brashi (2017) examined only 20, and Heidarnezhadian, Aliakbari and Mashhadi (2015) checked only 30, such studies correlated collocations and different aspects of the language. The importance of collocations is beyond dispute; still, lack of similar studies in the Tunisian context makes the study at hand of paramount importance.

\section{Methodology}

\subsection{Design}

To scrutinize the Tunisian EFL learners' familiarity with English collocations, awareness of phraseology, and correlating collocation with learners' achievements in writing and oral skills, the current study adopts a mixed method approach. The design of the study is of quantitative and qualitative type. For a correlational analysis, it embarked on assessing the performance of a sample of 
Tunisian learners of English as an L3 and the level of collocation competence of the learners in question. Besides reviewing the available literature, the study design involved descriptive analysis employing quantitative and qualitative methods and techniques of data collection as disused below.

\subsection{Participants}

The participants recruited in the study were 84 Tunisian EFL learners doing their second and third year of the EFL program at the Higher Institute of Applied Languages and Computer Sciences, Béja, Tunisia. They were 20 males and 64 females, aged between 19 and 23. They were assumingly sociolinguistically identical. They are native speakers of Tunisian Arabic (the local dialect/variety) with French being the second dominant language in the country. They also learn English as an L3. This sample represented a fairly homogeneous group in terms of schooling history and intermediate English proficiency level. As English is not playing a crucial role in the country, learning English was less important than French. However, the students in question joined the department of English for certain purposes.

\subsection{Instruments}

Three research tools were used to collect data: a collocation test, focus-group discussion, and document analysis. Each of these tools in outlined below.

\subsubsection{Collocation Test}

To elicit the subjects' collocation competency, a test was designed for this purpose. It consisted of three parts: multiple-choice questions (40 items), fill-in gap Questions (40 items), and translation from L1 into L2 and vice-versa (20 items). The test was adopted from Gyllstad' (2007) book, Testing English Collocations, and some previous studies, viz. Kamal (2014) and Namvar (2013) and Begagić (2014). Besides idiomatic expressions and phrasal verbs, the test was made up of both lexical and grammatical collocation as proposed by Benson, Benson, and Ilson (1997). Guided by the research objectives, the test was designed to specifically examine the following collocation patterns: noun + noun pattern; adjective + noun pattern; verb + noun pattern; adjective + preposition pattern; phrasal verb pattern (verb + adverb or preposition); adverb+ adjective pattern; and adverb + adjective (see Appendix A). Being adapted from other sources, the test was piloted on a small sample of similar characteristics, and it was found psychometrically appropriate.

\subsubsection{Focus- Group Discussion}

Having tested the informants' collocation competence, a follow-up focus group interview was conducted to enlarge the scope of investigation - to ask the participants about their perceptions about English collocations, and how they rationalize learning them. The discussion session lasted for about an hour and a half. Questions were developed beforehand, and emergent questions were added during the discussion. Data were gathered through field notes, recordings and transcripts were analyzed later on. For emerging themes, data were analyzed using an iterative process. Focus group data were coded, classified and reported.

\subsubsection{Document analysis}

Available documents such as course descriptions, timetable and journals, results of written and oral tests and samples of students' diaries, SMS and emails were also included as documents that add to the pot of data. Some examples of the collocational patterns were extracted from these documents to illustrate some points in the analysis section.

\subsection{Procedures}

The first step was testing the participants' collocational competence skills- their level of using English collocations in oral and written discourse. The tests are administered by the researcher with the help of two volunteering teachers who taught the target population during the same period of conducting the study. Each test was administered separately. Having analyzed the tests, a focus-group interview was conducted. Having collected the data as for the test scores, a focus group of 12 participants was adopted to enrich the topic of association between collocations and oral skills, errors of using collocations and some other related issues. The author -who is primarily a teacher at the site of study- 
initiated and headed the discussion, and he maintained the focus on English collocation in the Tunisian context. He invited another colleague and introduced him to the subsample as a guest speaker. The guest speaker, who is a professor of linguistics at the same institution, took notes. Throughout the discussion, the author maintained eye contact and motivated the whole group to interact giving chances for everyone in the group to speak. After the discussion session, the researcher discussed the results of this meeting with the guest speaker to enlighten some important ideas linguistically and pedagogically. Data gleaned from this focus-group discussion were code, screened and analyzed later one.

Similarly, necessary data were obtained from document analysis. Available documents in the institution where the study was conducted were looked into and embedded in the analysis where appropriate. Documents such as the timetable, the course descriptions and the informants' diaries and notebooks contained important data that enriched the analysis by showing the status of collocations in their daily English usage.

Prior to data collection, an official approval was obtained from the administration to conduct such a research project, meet the participants and access relevant official data and academic records of the respondents. The informants were not compelled to take part in the study. They were assured that their participation in the collocation test and focus-group dissuasion would be confidential and will not affect their academic achievements. The participants' names and test scores were not put for the public.

\subsection{Data Analysis}

Basically, the study aimed to (a) uncover the Tunisian EFL learners' familiarity with English expressions (idioms, phrasal verbs, and collocations) with a focus on collocations, (b) explore the students' awareness of phraseology, (c) identify how they linguistically violate the usage of collocation, and (d) correlate their collocational competence with performance in spoken and written English. The first three objectives were satisfied by data gleaned from a test of collocation and qualitative data collected from the focus-group discussion, and the third objective was achieved by using a correlation analysis; the participants' writing and oral skill scores -as documented in their academic records (documents analysis)- were correlated with the collocation test scores. The package of data was screened, cleaned, processed, and analyzed. The descriptive statistical analysis was carried out by using the SPSS 21 with the help of a statistician. The correlation between the variables of the study (English collocation learning and oral and written skills) was measured statistically using Spearman correlation coefficient. In this study, the analysis was based on seven patterns of collocation. The informants' answers to the collocation test were converted into percentages, and qualitative data (open responses in the focus-group discussion) were accumulated and categorized. Other data ensuing from documents were subject to content analysis.

\section{RESULTS}

The analysis framework is laid down in this section according to the sequence of the research questions. The analysis is strengthened by a flashback on the literature; it was done in such a way to compare the Tunisian EFL context to some other worldwide contexts.

\subsection{Q \#1: To what extent are the Tunisian users of English familiar with English collocations?}

This question can be put in another way: To what extent are learners aware of collocations roles in mastering L2? In either way, it measures the informants' abilities in using English collocations. To find answers to this question, a test of English collocation (see Appendix A) was administered and the results are outlined in Table 1 and Figure 1. The test comprised 100 items with ten items for each collocational pattern. The test scores were obtained and processed by using SPSS. The results show that the respondents were quite unfamiliar of the English collocations. They scored less than 50 points out of 100. The descriptive statistics of the test were calculated and outlined in Table 1.

Table1. Descriptive Statistics of the Participants' Collocation Test

\begin{tabular}{|c|c|c|c|c|}
\hline No. of students & Total scores & Mean & Percentage & StD \\
\hline 84 & 84 & 29.30 & 49.32 & 4.21 \\
\hline
\end{tabular}


As the table shows, the students' ability about collocations was fair $($ Mean $=29.30)$, and percentage of $49 \%$. The standard deviation, however, was at 4.21 indicating that the whole group's collocation ability was close to each other. It was possible that the test was quite difficult for the informants since they were not exposed to ample collocational patterns in their EFL program.

The informants' collocation familiarity varied remarkably. Figure 1 illustrates their performance on the collocation test. As the data in the figure shows, out of the seven collocation patterns, the respondents' highest score was that of the phrasal verbs type with a percentage of $71 \%$ and $69 \%$ followed by adjective + noun $(61 \%)$, verb + noun $(52 \%)$, adjective + preposition $(51 \%)$, Noun + noun $(46 \%)$, verb + adverb (42\%), and adverb+ adjective (35\%) respectively. The results in Figure 1 are quite similar to the results of some previous studies in other EFL contexts. For instance, Mongkolchai (2008) and Wangsirisombat (2011) in the Thai context and Attar and Allami (2013) in the Iranian context showed similar results. That is to say, the varying degree of the Tunisian familiarity of English collocation and abilities in using the collocational patterns are no exception; EFL learners, in general, have similar problems of using collocations.

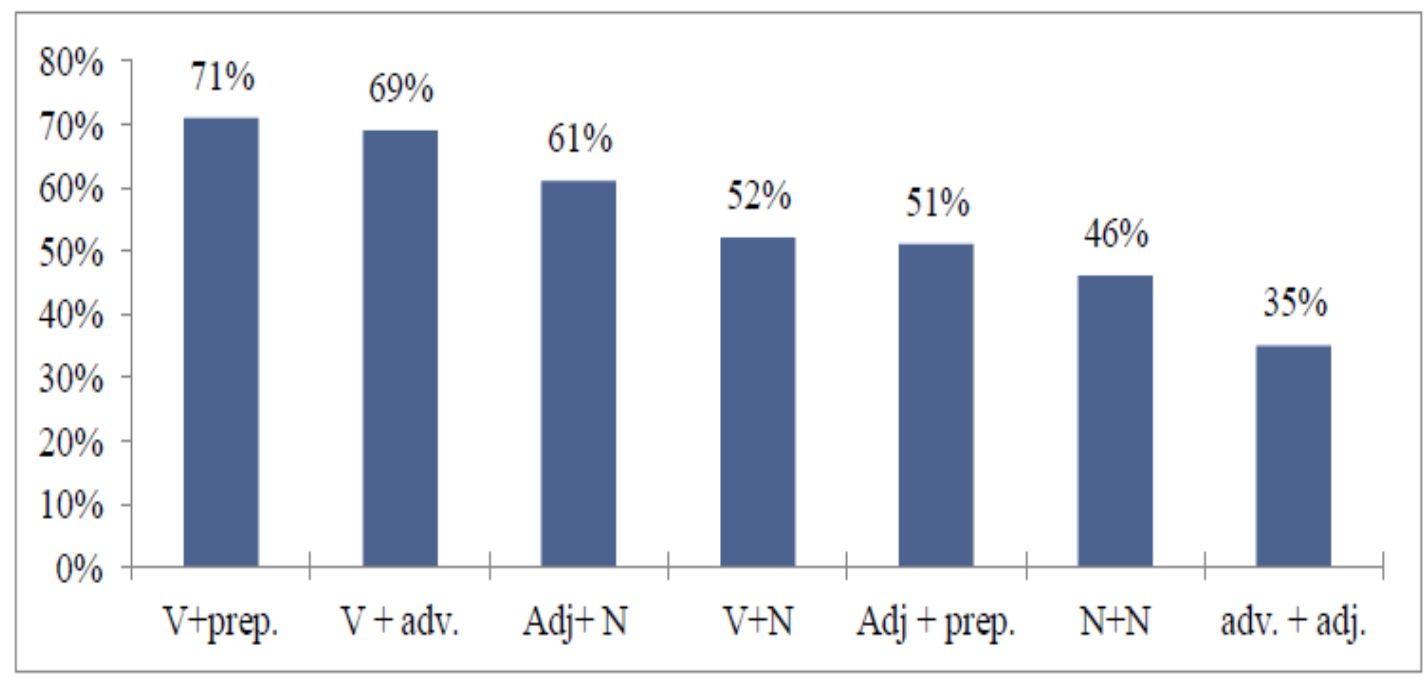

Fig1. The informants' abilities in Using Collocational Patterns

Data collected from the focus-group discussion illustrated that the informants were unaware of the collocational roles in learning English. Data gleaned from the discussion session generally indicated that the learners in question seem to be quite oblivious of the significance of collocations for English fluidity and proficiency. They stated that they were not overtly taught collocations in their university studies nor they were interested in learning things beyond the syllabus. They stated that they study such phraseological patterns, if any, mainly for the sake of passing exams. The students' knowledge of English collocation was rather limited. This is probably because they were not well-trained to use them, even at the pre-university levels. Collocations were not taught explicitly, and learners did not, therefore, pay attention to what falls beyond the classroom teaching/learning. As data in Figure 1 shows the learners' familiarity with phrasal verbs and idioms were the most noteworthy. This is probably because phrasal verbs and idioms are given due attention in the curriculum more than the other collocational patterns. In such a teacher-led environment, learners should be made aware of collocations of all types.

\subsection{Q \#2: What are the causes of Tunisian students' collocation violations?}

An analysis of the participants' uses of collocations reveals that the violations of collocational modeling are basically due to fourfold (as illustrated in Figure 2):

a) Informants' limited knowledge of collocations (38\%)

b) Application of the strategy of transferring L1 to L2 collocations (27\%)

c) The effect of the source text patterning (14\%)

d) Overgeneralization $(18 \%)$. 


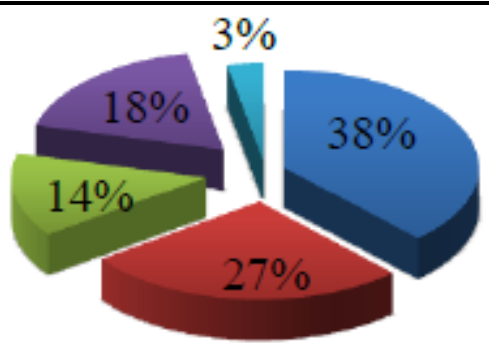

\section{limited knowledge \\ transferring patterning \\ overgeneralization}

Fig2. Sources of violations of Collocation patterning

The grounds of deficiency in using collocations were uncovered by recurrences of using these examples by the participants in the focus-group discussion. Similarly, an analysis of samples of the written discourse by these participants showed common errors, as illustrated in these examples: doing a toast, instead of making a toast; absolutely happy, instead of perfectly happy; and passed down, instead of passed away. Such errors reflect the gaps in the learner's knowledge of the target language and the idiomatic expressions in the target language. Noticeably, errors were systematic and predictable, resulting in the construction of some collocational patterning different from that of the target language. These errors result from learners' attempt to make use of their L1 (Arabic) or L2 (French) knowledge. When Tunisian students of English are not competent enough to use English collocations, they try to make use of Arabic or French patterns and grammatical rules, and this leads to erroneous collocations.

Besides L1 interference, learners tend to generalize the language knowledge acquired, that is, to formulate rules based on their learning experiences in order to apply these rules to new language materials. They tend to extend the uses of a grammatical rule or linguistic item beyond its accepted uses. When it comes to collocations, they tend to generalize the use of a particular word in a right collocation to make wrong collocations. For example, do harm to is correct collocation; learners tend to generalize the use of ' $d o$ ' in this phrase to make new phrases like *do good to and *do bad to, which are actually illegitimate in English. Likewise, * play computer is made by analogy to play the piano or play basketball, etc.

\subsection{Q \#3: Does the Tunisian EFL Students' Knowledge of Collocations Correlate with their Oral and written English Performance?}

The answer to this question is of a correlational type. It is an association between the informants' performance on a collocational test and their scores on oral and written performance. The results of the collocation test were obtained in a way as discussed above, and the scores of the oral and written performance were obtained through document analysis. The respondents' academic records were examined and their scores were used for this correlational analysis. The results of this associational analysis are outlined in Tables 2 and 3. Comparing the scores of the informants with their overall academic achievements indicates that there is a correlation between their performance in written and spoken skills in contrast with their scores in the collocation tests. Although their overall performance of the collocation test was low, it has been observed that the better the scores in the collocation competence, the better their overall English performance.

As for the impact of collocational knowledge on oral skills, Table 2 shows that there is a significant correlation (p-value $=.962$ ) at the 0.01 level, which is greater than .05 . This clearly supports that there is a relationship between subjects' oral proficiency as measured by their listening and speaking tests and knowledge of collocations as measured by their performance on the collocation test. This positive correlation is in harmony with the results of similar previous studies (e.g. Attar \& Allami, 2013; Yazdandoost, Saleh \& Kafipour, 2014) in the Iranian EFL context, and Biskri (2012) in the Algerian context, as well as Al-kadi (2014) in the Yemeni EFL context.

Table2. Correlation coefficient between Oral Skills and Collocations

\begin{tabular}{|c|c|c|c|}
\hline \multicolumn{1}{|c|}{ Collocations } & Collocation score & Oral skills score \\
score & Pearson correlation & 1 & $.962 * *$ \\
\hline \multirow{3}{*}{ Oral skills } & Sig, (2-talied) N. & 84 & 84 \\
& Pearson correlation & $.962 * *$ & 1 \\
& Sig, (2-talied) & .000 & 84 \\
\hline
\end{tabular}

** Correlation is significant at the 0.01 level (2-tailed) 
Likewise, the data displayed in Table 3 indicates that there is a significant correlation ( $p$-value $=.955$ ) at the 0.01 level, which is greater than .05 . That is, the participants' writing abilities were positively associated with their collocational performance. Based on this, it can be said that the current study supports the idea that there is a relationship between subjects' language proficiency as measured by their writing test scores and their knowledge of collocations as measured by their performance on a test of collocation (as explained earlier).

Table3. Correlation Coefficient between Writing Skills and Collocations

\begin{tabular}{|c|c|c|c|}
\hline \multirow{2}{*}{$\begin{array}{c}\text { Collocations } \\
\text { score }\end{array}$} & Pearson correlation & Collocation score & $.955^{* *}$ \\
& Sig, (2-talied) & 1 & 84 \\
\hline \multirow{2}{*}{ Writing } & N. & 84 & 1 \\
& Pearson correlation & $.955^{* *}$ & 84 \\
\hline
\end{tabular}

** Correlation is significant at the 0.01 level (2-tailed).

This implies that good collocational knowledge is an important indicator of writing proficiency. In other words, collocations enhance writing abilities. This result is congruent with the results of Mounya (2010) and Yazdandoost, Saleh and Kafipour (2014) that English collocations are positively correlated with the writing competence of EFL learners.

\section{DisCuSSION}

The results laid in Section 6 indicate that the informants' ability in using collocations was generally inadequate. The findings showed that the informants' ability in the phrasal verbs (Verb + preposition or adverb) was higher than their performance on the other six collocational patterns (see Figure 1) as demonstrated by the collocational test. Perhaps, this is due to the fact that phrasal verb patterns were the most remarkable collocation patterns in the Tunisian English curriculum and course descriptions. Hence, the participants were familiar with this patterning more than the other ones. Although researchers and linguists (e.g. Ur, 1996; Richards, 2002; Thornbury, 2009; Yazdandoost, Saleh \& Kafipour, 2014) postulate that collocations are important in learning English, the Tunisian learners of English, which is a third language in the country, do not generally show a high proficiency in using collocations in their oral and written tasks. Learners are quite unacquainted with collocations' roles in acquiring their third language. This is basically due to insufficient exposure to the target language (English) in their daily life. Besides, this is probably because collocations are arbitrary and not straightforwardly teachable (Attar \& Allami, 2013; Hadi, 2014; Kamal, 2014; Kiaee, Moghaddam \& Hosseini, 2013). Another explanation stems from Shehata's (2008) findings that the environment (ESL or EFL) fosters the success of mastering collocations.

Being an additional language with no social prestige in Tunisia, English learners tend to give it marginal importance in their linguistic interests. This results in a lack of phraseological awareness on the part of learners who seem to focus mainly on individual words rather than lexical items consisting of more than a single word (chunks). It is also seen in the learners' beliefs- as revealed in the focus group discussion - concerning their ambitions and aims for studying English; even though they acknowledged that they were unaware of what collocations are. Further, the learners in focus tend to learn large numbers of words rather than studying how words collocate.

As for sources of violations of the English collocational patterning, the sample deviation of collocations was basically due to four reasons (as illustrated in Figure 2). First, this may be explained by the interference with the mother-tongue (Arabic) and second language (French). Second, Tunisians' collocational errors are based on some correct collocations (i.e., neglecting restrictions and exceptions). For instance, based on the correct collocations take measures and commit a crime, Tunisian students have been frequently observed using phrases such as *make/take some activities and *commit a mistake. They use the phrase *commit a mistake which is generalized from the correct collocations of commit (such as commit a murder, commit theft, commit suicide, etc.). The words following the word commit all have negative connotations, and not all nouns sharing negative connotations can be used together with commit. Similarly, although 'mistake' has a negative connotation, make a mistake is the correct collocation. Plausibly, the students violated collocational patterns because they applied the strategy of synonymy when deciding which collocates should be 
used. Moreover, they might have low or limited knowledge of collocational specialization. The following examples have been taken from excerpts of their dairies, SMS, emails, etc.: a newspaper booth, instead of a newspaper kiosk; environmentally- elaborate, instead of environmentally-friendly; had the first prize, instead of won the first prize); takes aside, instead of takes after; risen strongly, instead of risen sharply; or wonderfully productive, instead of remarkable productive.

As the results of the correlation show that the Tunisian EFL students' knowledge of collocations predicts their language skills performance. The findings also have demystified a positive correlation between collocation and oral skills. The participants who actively took turns in the focus-group discussion were good users of collocations.

\section{RECOMMENDATIONS AND SUGGESTIONS}

\section{Raising Awareness}

Raising awareness of collocation can be incorporated in the collocation teaching/ learning process so as to efficiently expand the learners' mental lexicon. Collocations should be incorporated in English language syllabus to enhance effective language learning. Teachers should train students to think of what is beyond the word level. They should encourage learners to look for a multiple-word expression (the way words combine into chunks) rather than getting used to mono words separately. Becoming aware of collocations might be a first step that leads to internalizing/learning collocations by frequent exposure to words that collocate together.

\section{Learning and Teaching Strategies}

As for students of English, frequent experience of learning materials written in the native language is very important. Students should be encouraged to listen to or read genuine English (by native speakers). Doing this, they sound more native-like because immersion in native idiomatic English is helpful for developing a good sense of English collocations. So far as the concrete techniques of learning collocation are concerned, students can make use of rich resources of dictionaries and the Internet applications. Nowadays, there are many useful dictionaries of collocation. Oxford Collocations Dictionary for Students of English is a case in point. All its collocations are listed sequentially according to the frequency of each collocation. As mentioned in the dictionary Preface, it is "no matter how convinced learners are in principle of the importance of collocation, it is difficult for them to put these principles into practice without the benefit of an up-to-date, corpus-based dictionary of collocation." Although using such a dictionary might be useful in meeting the needs of learners and teachers but still, there is a need to invent some other teaching and learning strategies that suit the local context. Learners and teachers can develop their own ideas and strategies to enhance collocation acquisition.

\section{Extending Learning Beyond the Classroom}

Extending learning beyond the classroom enables the learners to harness online resource for free, autonomous, and useful language learning. The Internet provides several platforms for practicing collocations online. There are many free corpora on the Internet for learning how to use a word and its associated words (i.e. its collocation). A good example is BNC (British National Corpus) which is accessible by searching for it through 'baidu', see Figure 3 below.

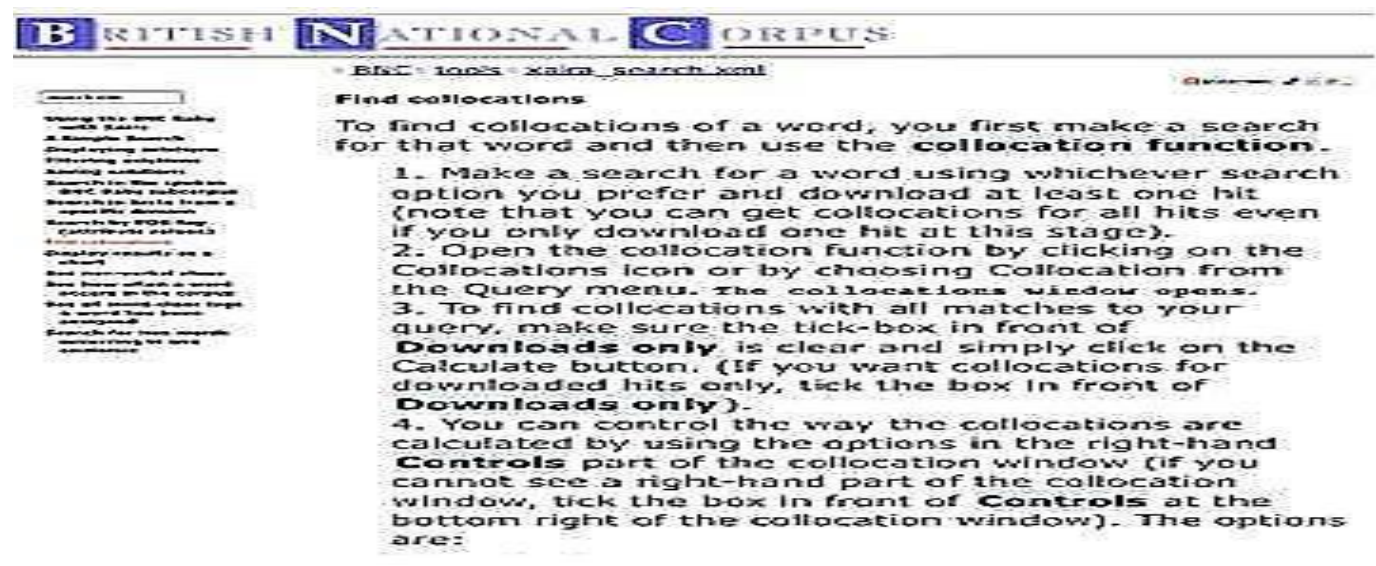

Figure3. British National Corpus online 
Advanced learners of English can test their abilities in using collocations and get timely feedback using http://www.english-in-chester.co.uk/e-learning/lesson/collocations/ This platform, among others, provides several exercises on using various patterns of collocations. For example, as Figure 4 shows, in English it is normally said alphabetical order, not any of the other choices in the list.

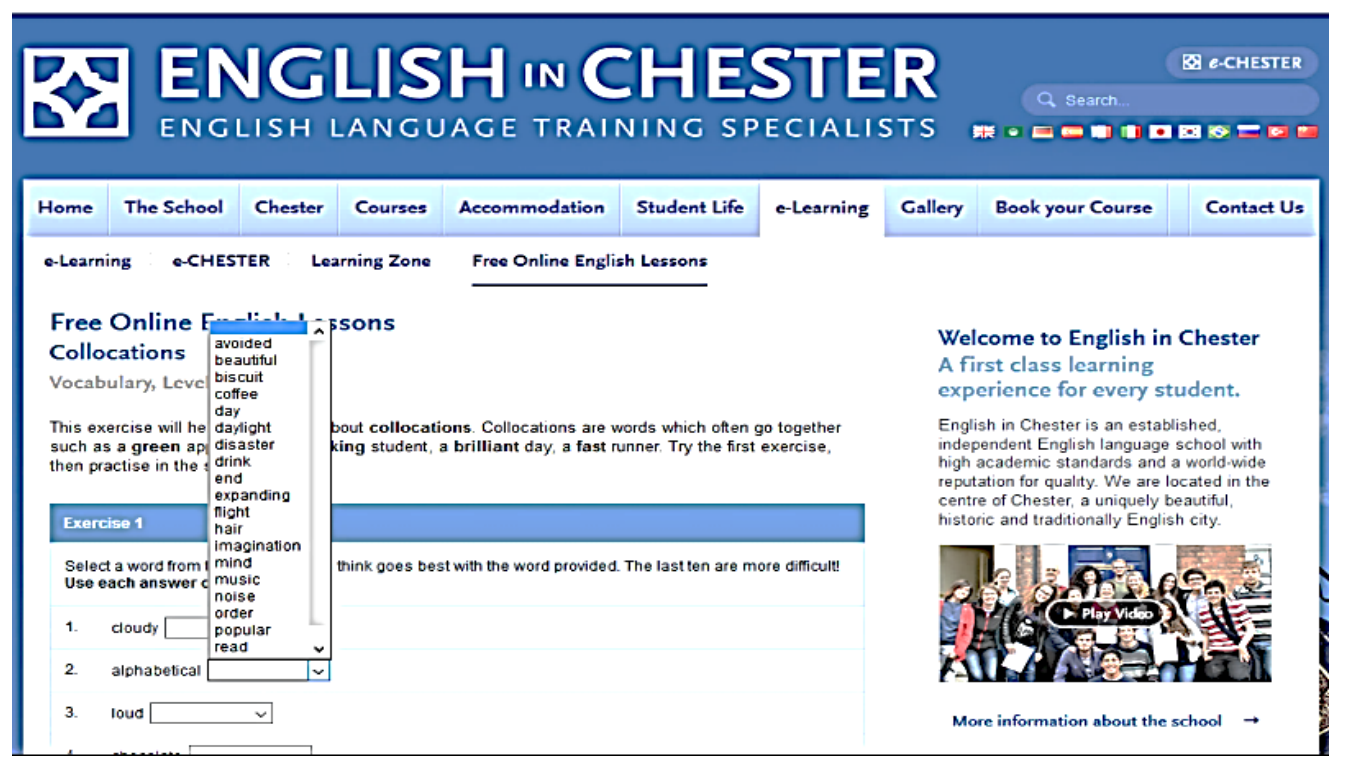

Figure4. An example of online collocations exercises

Figures 3 and 4 illustrate the availability of online possibilities to access lessons and test as well as get feedback without the need for a rigid syllabus or classroom teaching. However, collocations are better integrated into the classroom teaching with a guidance of the teachers. It would be more appealing to give learners activities that they perform and link them to what they learn in the textbooks.

\section{Conclusion}

This study elucidated the status of English collocations in the Tunisian EFL context by looking into the performance of a sample of EFL learners using a bunch of collocations. The results warrant four areas of discussion (a) ability in using collocations, (b) source of violating correct uses, (c) correlation between using collocation and performance, and (d) awareness of the importance of phraseology for L2 competency. Data collected through a collocation test, focus-group discussion, and document analysis show that the overall collocational competence of the informants was quite unsatisfactory. Learners tend to neglect collocations unless they are told by their teachers to use them. This is probably because collocations are arbitrary and not governed by particular rules; this makes it an unappealing area of language; the learning and teaching environment of this study was grammarbound and teacher-centered. As a result, learners tend to prefer things which are rule-driven and things which are taught not things which they may learn on their own.

Although some previous studies recommended some implicit and explicit teaching rules of collocations, there is no such rule of thumb to tackle the difficulties of the linguistic behavior of collocations. Students should be advised to employ strategies of acquiring collocations and using them in everyday English, not memorizing them for merely passing exams. There should be insightful perspectives to enhance collocational teaching and the curriculum development more than focusing on mono words and grammar. The findings of this study disclosed that the students' ability in using phrasal verbs as major types of collocational patterns was higher than their abilities to use other patterns of collocations. Successful learning of collocations depends largely on the mastery of their typical collocational behavior more than governing rules that some other aspects of English run through. To increase the learners' abilities in using collocations, teachers should promote learners' awareness of the importance of collocational knowledge. When learners are aware of collocation competency for their overall English competency/proficiency, they (learners) may exert more efforts to improve performance in collocations. Additionally, students should make use of collocation dictionaries and relevant resources on the Internet not only in the classroom but also whenever they 
have chances to do so. This yields insights for teachers to promote mobile and autonomous learning (extended beyond the classroom teaching).

If the students choose the right collocation in communication, they become able to clearly communicate more naturally. If learners' sensitivity to various relations between words is not highlighted enough or words are not learned in chunks, learners are not bound to approach the nativelike level of proficiency.

Driven by the nature of the study, the findings are neither meant to be generalizable to the population at large nor extrapolated to other contexts. The main purpose of the inquiry was deepening understanding of how collocational behavior is tackled by a sample of the Tunisian learners of English as a third language not only in the country but also in the region. It is hoped that future researchers may explore students' collocation competence by using other research instruments or using a bigger sample. A suggested research topic is an elaborated description of collocations in the curriculum at schools and university level. Also, tracing the way teachers teach and include collocations in their classes might be an interesting topic for some researchers. Diagnosing challenges and surveying strategies of learning collocations by the Tunisian EFL learners are enduring research avenues.

\section{ACKNOWLEDGMENTS}

I would like to express my gratitude to the professors who provided some comments on the preliminary version of this paper by validating the instruments of data collection. Similarly, I would like to extend thanks to the teachers who volunteered to assist me in getting the necessary data and cooperated with me throughout conducting this research paper. A note of thanks goes to my students who patiently took part in the study- taking the collocations test, participated in the focus-group discussion, and allowed me to analyze some excerpts of their emails, written texts, and relevant discourse.

\section{REFERENCES}

[1] Alhaysony, M. (2017). Strategies and difficulties of understanding English idioms: A case study of Saudi university EFL students. International Journal of English Linguistics, 7(3), 70-84.

[2] Al-Khawaldeh, N. Jaradat, A., Al-momani, H. \& Bani-Khair, B. (2016). Figurative idiomatic language: Strategies and difficulties of understanding English idioms. International Journal of Applied Linguistics \& English Literature, 5 (6), 119-133.

[3] Attar, E. \& Allami, H. (2013). The effects of teaching lexical collocations on speaking ability of Iranian EFL learners. Theory and Practice in Language Studies, 3(6), pp. 1070-1079.

[4] Aouina, H. (2013). Globalization and language policy in Tunisia: Shifts in domains of use and linguistic attitudes (Ph.D. dissertation), the University of the West of England. http://eprints. uwe.ac.uk/20212.

[5] Benson, M., Benson, E., \& Ilson, R. (1997). The BBI Dictionary of English word combinations $\left(2^{\text {nd }}\right.$ ed.). Amsterdam, the Netherlands: John Benjamins Publishing Company.

[6] Brashi, A. (2017). Collocability as a problem in L2 production. Rejections on English Language Teaching, 8(1), pp. 21-34.

[7] Begagić, M. (2014). English language students' productive and receptive knowledge of collocations. Explorations in English Language and Linguistics) 2(1) 46-67. DOI:10.1515/ exell2016-0003

[8] Bhumadhana, S. (2011). A Study of the use of academic verb collocations and the English writing ability of undergraduate English-major students. OJED, 6(1), 1891-1905.

[9] Boukadi, S. (2013). Teachers' perceptions about the future of English language Teaching and Learning in Tunisia after the 2011 revolution ( $\mathrm{PhD}$ dissertation). University of Exeter.

[10] Biskri, Y. (2012). The effect of lexical collocation awareness-raising on EFL students' oral proficiency (MA thesis). Faculty of Letters, Human and Social Sciences, Badji Mokhtar University of Annaba, Alegria. 
[11] Brown, D. (2000). Teaching by principles: An interactive approach to language pedagogy. Longman Press.

[12] Castro, M. \& Faber, P. (2014). Collocation dictionaries: A comparative analysis. Monografías de Traducción e Interpretación, 6, 203-235.

[13] Crowther, J. (2003). Oxford Collocation Dictionary for Students of English. Beijing: Foreign Language Teaching and Research Press.

[14] Daoud, M. (2000). LSP in North Africa: Status, problems, and challenges. Annual review of Applied Linguistics, 20, 77-96.

[15] Daoud, M. (2001). The linguistic situation in Tunisia. Current Issues in Language Planning, $2(1), 1-52$.

[16] Duan, M. \& Qin, X. (2012). Collocation in English Teaching and Learning. Theory and Practice in Language Studies, 2 (9), pp. 1890-1894. doi:10.4304/tpls.2.9.1890-1894

[17] Gyllstad, H. (2007). Testing English Collocations: Developing Receptive Tests for Use with Advanced Swedish Learners. Lund: Media-Tryck.

[18] Hadi, S. (2014). Iraqi EFL Learners' use of English lexical collocations. Journal of Nabil University, 22(3), 566-578.

[19] Heidarnezhadian, Q. Aliakbari, M. \& Mashhadi, J. (2015). The Potential Impact of using prefabricated patterns (Collocation Expressions) on improving writing proficiency among Iranian intermediate EFL Learners. International Research Journal of Applied and Basic Sciences, 9(30), 328-334.

[20] Kamal, O. (2014). Investigating the effect of explicit and implicit instruction on the acquisition of verb + noun collocations: a case of L2 Egyptian learners (MA thesis). School of Humanities and Social Sciences the American University in Cairo.

[21] Koprowski, M. (2005). Investigating the usefulness of lexical phrases in contemporary coursebooks. ELT Journal, 59 (4), 322-332.

[22] Kiaee, S. \& Moghaddam, N. \& Hosseini, E. (2013). The effect of teaching collocations on enhancing Iranian EFL learners' reading comprehension. Journal of advances in English language teaching, 1(1), pp. 1-11.

[23] Labassi, T. (2008). On responsible uses of English: English for emancipation, correction, and academic purposes. Changing English, 15(4), 407-414. DOI: 10.1080/13586840802493050

[24] McCarthy, M. \& O'Dell, F. (2005). English Collocation in Use. Cambridge university press.

[25] Mongkolchai, A. (2008). A study of university students' ability in using English collocations (MA thesis). Srinakharinwirot University, Thailand.

[26] Mounya, A. (2010). Teaching lexical collocations to raise proficiency in foreign language Writing: a case study of first-year English students at Guelma University, Algeria (MA thesis). Universite Mentouri, Constantine, Algeria.

[27] Namvar, F. (2013). The relationship between language proficiency and use of collocation by Iranian EFL students. The Southeast Asian Journal of English Language Studies, 18 (3), 41 - 52.

[28] Nofal, K. (2012). Collocations in English and Arabic: A comparative study. English Language and Literature Studies, 2(3), 75-93.

[29] Oxford Collocations Dictionary. $2^{\text {nd }}$ Edition. (2009). Oxford University Press.

[30] Shehata, A. (2008). L1 influence on the reception and production of collocations by advanced ESL/ EFL Arabic learners of English (MA thesis). Department of Linguistics, College of Arts and Sciences, Ohio University.

[31] Shiri, A., Sadighi, F., Azizi, M. \& Nekoueizadeh, M. (2017). The nature of lexical collocational errors committed by advanced Iranian learners of English. Journal of Languages and Culture, $8(1), 1-9$.

[32] Shahryari, N. \& Motaharinik, S. (2015). Collocation instruction and its influence on relationship between essay writing and speaking ability. Indian Journal of Fundamental and Applied Life Sciences, 5 (S3), pp. 1163-1169. 
[33] Wangsirisombat, N. (2011). A study of collocational errors in Thai EFL learners' writing (MA thesis). Language Institute, Thammasat University, Bangkok, Thailand.

[34] Yazdandoost, Z., Saleh, E. \& Kafipour, R. (2014). The relationship among collocation knowledge and listening, speaking, reading and writing proficiency of Iranian EFL learners. Language, Individual \& Society Journal of International Scientific Publications. www.scientificpublications.net

\section{AUTHOR's BIOGRAPHY}

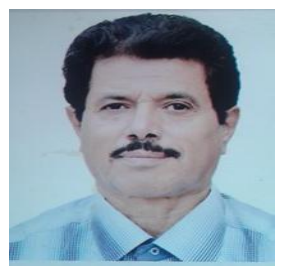

Hussien Almaktary is an assistant professor of English language, majoring in ELT and curriculum. He obtained his Master of Education (TESOL) from University of Leeds in Britain, and $\mathrm{PhD}$ of Education (Curricula \& Teaching EFL) from Alexandria University, Egypt. He is currently working for Jendouba University, the Higher Institute of Applied Languages and Computer Sciences, Béja, Tunisia. His areas of interest also include French, Arabic, grammar, and poetry.

Citation: Hussien, Almaktary. "English Collocations In The Tunisian EFL Context." International Journal on Studies in English Language and Literature (IJSELL), vol 5, no. 8, 2017, pp. 4-20. doi:http://dx. doi.org/10.20431/2347-3134.0508002.

Copyright: () 2017 Authors. This is an open-access article distributed under the terms of the Creative Commons Attribution License, which permits unrestricted use, distribution, and reproduction in any medium, provided the original author and source are credited. 